\title{
UHF RFID Tag Based on Modified Dihedral Corner for Enhanced Read Range and Broadband Operation.
}

\author{
Fijo Jose $\mathbf{K}^{1^{*}}$, Aju John K.K², Thomaskutty Mathew ${ }^{3}$ \\ ${ }^{1}$ School of Technology and Applied Sciences, Mahatma Gandhi University, Regional centre, Edappally, Kerala, India \\ * E-mail: fijomwrfegmail.com
}

\begin{abstract}
This paper presents the design and development of a novel UHF RFID tag which exhibits enhanced read range over the entire UHF RFID band of $860-930 \mathrm{MHz}$. This novel UHF RFID tag consists of an antenna based on modified dihedral corner with an embedded double T-match and a Murata LXMS 31ACNA010 chip attached to the terminals of the antenna. Measured read range variations over the azimuth and elevation angular ranges show enhanced read range over wide angular ranges as compared to conventional RFID tags.
\end{abstract}

\section{Introduction}

Radio Frequency Identification (RFID) is an automatic identification method based on data storage and backscattering [1]. Various RFID systems use different frequency bands like Low Frequency (LF, 125 - $134 \mathrm{kHz}$ ), High Frequency (HF, $13.56 \mathrm{MHz})$, Ultra High Frequency (UHF, 860 - 960MHz) and Microwave (MW, $2.45 \&$ $5.8 \mathrm{GHz}$ ). The long read range, high read rate and large information storage capacity of the UHF RFID systems have resulted in the widespread use of this systems in supply chain managements and other applications. A passive backscattering UHF RFID system generally consists of two basic components, a reader and a tag, in which the reader and the tag communicate with each other by using electromagnetic waves. The reader uses an antenna to transmit an electromagnetic wave to wake up the passive tag, which is mounted on the object being identified. The tag consisting of an antenna and a chip, responds by backscattering the electromagnetic wave which is modulated by the data stored in the chip. RFID tag antenna must be conjugately matched to the impedance of the chip for enabling maximum power transfer to the chip and thereby resulting maximum read range for the RFID tag. Several researchers published papers on the design of UHF RFID tags and their performance evaluation employing different methods like read range measurement, antenna impedance measurement, radar cross section (RCS) evaluation etc. [24]. Many of the basic designs of the UHF RFID tags were based on dipole and folded dipole structures [5-6]. The main challenge in the modern UHF RFID tag design is to develop a miniaturized tag antenna with appreciably good read range characteristics. Dipole structures with meandered arms are effective in the development of miniaturized RFID tag antennas and are widely employed in various designs [7, 8]. T-matching technique is widely used in the design of RFID tags for achieving the impedance matching between the tag antenna and the chip [9-10]. Manju et al. reported, an UHF RFID tag composed of modified multi-fractal cantor arms for enhanced read range. Good impedance batching between the chip and the tag was achieved by optimizing the iterated function system (IFS) coefficients of the multi-fractal cantor geometry and the dimensions of the embedded T-match [11]. Designing of an UHF RFID tag with broadband characteristics over the entire UHF RFID band (860$960 \mathrm{MHz}$ ) is a requirement for the universal deployment of RFID tags. Recently various techniques for producing miniaturization and broadband characteristics were attempted by many researchers [12-14]. Jibish et al. designed a UHF RFID dipole tag antenna with tapered meandered arms for better broadband characteristics and miniaturization [15]. Split Ring Resonator (SRR) is topic of immense interest in electromagnetics and was investigated by many researchers for various applications in antenna designs. Aju et al. reported a compact UHF RFID tag for broadband operation. The miniaturization and broadband characteristics were achieved by loading square split ring resonator (SRR) symmetrically on both arms of the dipole with short circuited strip between the SRRs [16].

Many researchers have studied the back scattering properties of perfectly conducting as well as loaded dihedral corner reflectors [17-20]. A right angled corner reflector provides a large back scattering over a wide angular range in a plane normal of its wedge [21-24]. The possibility of using dihedral corner in the design of UHF RFID tags with enhanced read range has not been seen in literature. An enhanced read range of the UHF RFID tag is a prime concern in applications like vehicle identification, toll collection, and sensor based RFID etc.

In this paper we propose a novel UHF RFID tag based on modified dihedral corner with embedded double T-match which exhibits enhanced read range and broadband characteristics over wide azimuth and elevation angular ranges. 


\section{UHF RFID tag Design and Testing}

The simulation software CST Microwave studio suite is used for the design of the proposed UHF RFID tag based on modified dihedral corner. Configuration of the proposed UHF RFID tag based on modified dihedral corner is illustrated in Figure1. Figure 1(a) and 1(b) shows the front and back views of the proposed tag respectively. The proposed structure is developed using FR-4 substrate with metallic backing. The tag antenna consists of a $90^{\circ}$ dihedral corner with the corner edge truncated. An embedded double T-match is incorporated on the truncated face with an RFID chip Murata LXMS 31ACNA010 with an impedance of 12$\mathrm{j} 107 \Omega$ at $866 \mathrm{MHz}$ with threshold power of $-8 \mathrm{dBm}$ connected between the terminals of the antenna. A good conjugate impedance matching between the input impedance of the modified dihedral corner antenna structure and the chip impedance is essential for maximizing the read range. Then the antenna structure is simulated and the parameters are optimized to achieve close conjugate matching with the chip impedance at $866 \mathrm{MHz}$.

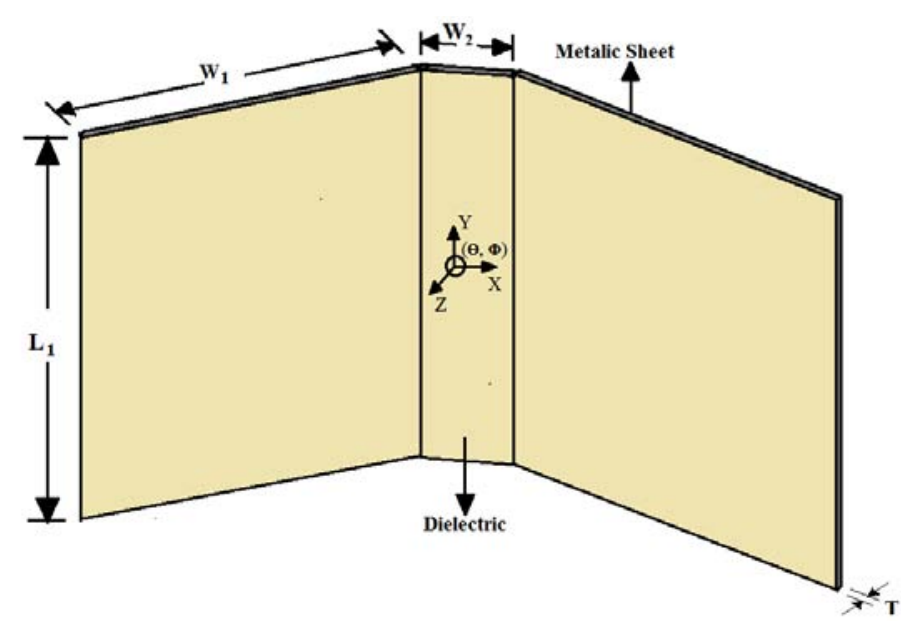

(a).

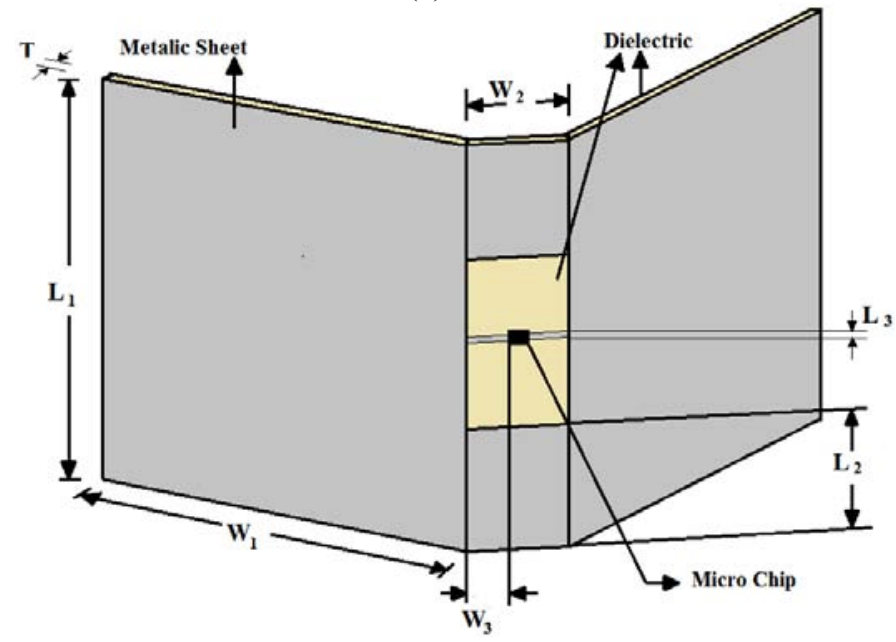

(b)

Figure 1: Configuration of UHF RFID tag based on modified dihedral corner.

(a) Front View, (b) Back View.
Optimized parameters are $\mathrm{L}_{1}=75 \mathrm{~mm}, \mathrm{~L} 2=16 \mathrm{~mm}, \mathrm{~L}_{3}=$ $0.5 \mathrm{~mm}, \mathrm{~W}_{1}=65 \mathrm{~mm}, \mathrm{~W}_{2}=15 \mathrm{~mm}, \mathrm{~W}_{3}=6 \mathrm{~mm}, \mathrm{~T}=1.6 \mathrm{~mm}$. The tag antenna with these optimized parameters is fabricated on FR-4 substrate of thickness $1.6 \mathrm{~mm}$ with relative permittivity $\epsilon_{\mathrm{r}}=4.3$. The simulated results of the variations of input resistance and reactance with frequency for the proposed UHF RFID tag based on modified dihedral corner are plotted in fig. 2 .

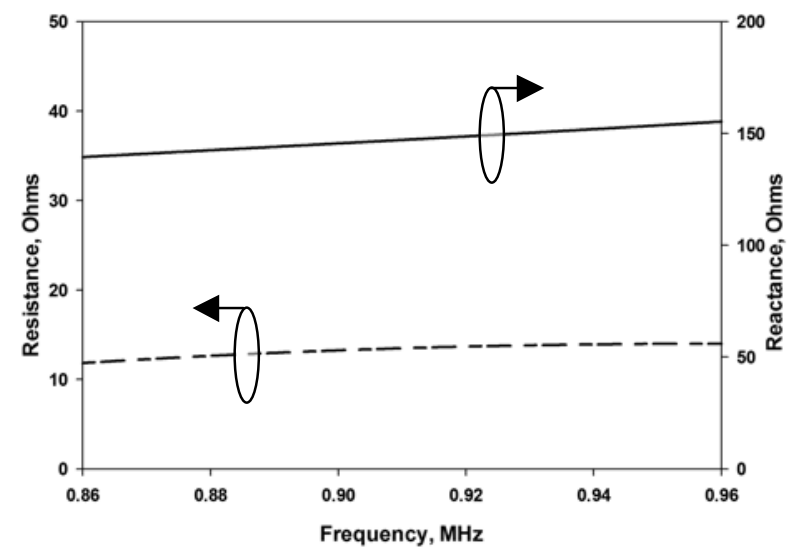

Figure 2: Variations of input resistance and reactance of the proposed UHF RFID tag based on modified dihedral corner.

It can be seen from the figure that the resistance and reactance of the antenna $12.083 \mathrm{ohms}$ and $140.34 \mathrm{ohms}$ respectively at $866 \mathrm{MHz}$, which results in a close conjugate matching with the chip impedance.

The efficiency of every RFID tag depends on its read range. The read range is the maximum distance at which the RFID tag can be detected. The read range ' $r$ ' can be calculated using Friis free-space formula as

$$
r=\frac{\lambda}{4 \pi} \sqrt{\frac{P_{t} G_{t} G_{r} \tau}{P_{t h}}}
$$

Where ' $\lambda$ ' is the wavelength, ' $P_{t}$ ' is the power transmitted by the reader, ' $G_{t}$ ' is the gain of the transmitting antenna, ' $G_{r}$ ' is the gain of the receiving antenna, ' $P_{t h}$ ' is the minimum threshold power necessary to provide enough power to the RFID tag chip, and ' $\tau$ ' is the power transmission coefficient given by

$$
\tau=\frac{4 R_{c} R_{a}}{\left|Z_{c}+Z_{a}\right|^{2}}, 0 \leq \tau \leq 1
$$

Where ' $Z_{c}=R_{c}+j X_{c}$ ' is the chip impedance and $Z_{a}=R_{a}+j X_{a}$ is the antenna impedance. The read range measurements of the proposed tag were taken with the help of an RFID Reader STA IR0507E with a reader sensitivity of $-80 \mathrm{dBm}$ and EIRP of $4 \mathrm{~W}$ with circularly polarized waves 


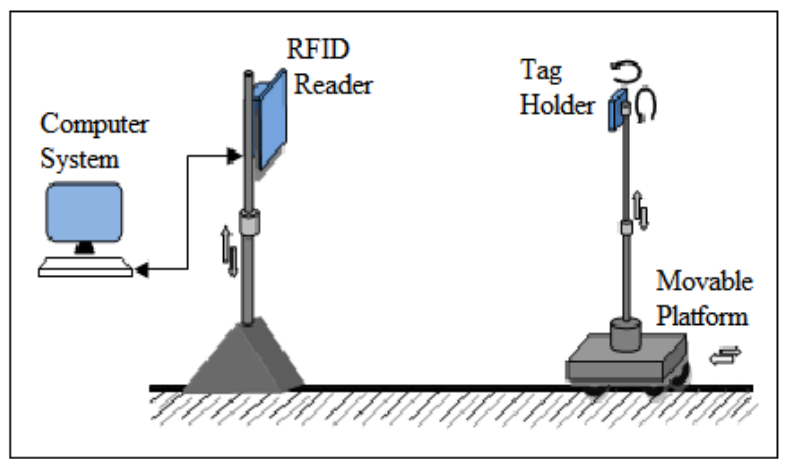

Figure 3: Setup for read range measurements.

Fig.3. shows the set-up for the read range measurement of RFID tags. RFID reader is at one side and the tag is fixed on the other stand, which can be moved to and fro. There is also an arrangement for placing the tag for different orientations in azimuth and elevation angular ranges. With the help of this arrangement the proposed tag fixed on the movable stand and the read range measurements were taken.

\section{Results and Discussion}

The photograph of the fabricated UHF RFID tag based on modified dihedral corner is shown in figure. 4 .

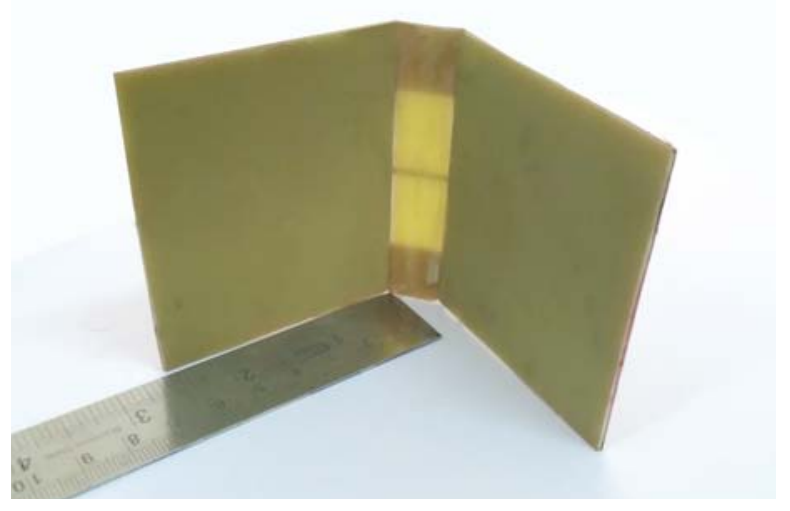

(a)

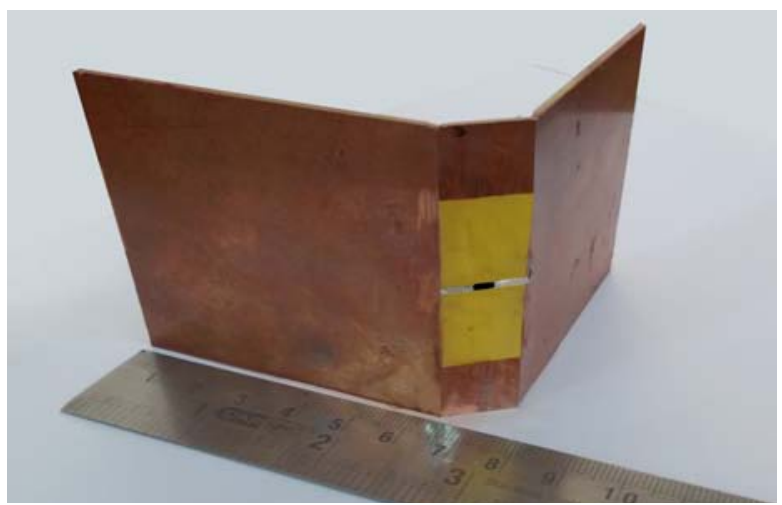

(b)

Figure 4: Photograph of UHF RFID tag based on modified dihedral corner.

(a) Front View, (b) Back View.
The measured variations in read range with frequency of the proposed UHF RFID tag based on modified dihedral corner over entire UHF RFID band $(860-930 \mathrm{MHz})$ is illustrated in Fig.5. It can be seen that a read range of 7.4 meters is observed for European RFID band $(866 \mathrm{MHz})$. It is also observed that the proposed RFID tag exhibits a read range of 7.3 meters at $915 \mathrm{MHz}$ (North American) and also 6.7meters at $920 \mathrm{MHz}$ (Chinese) it is evident that the proposed RFID tag exhibits enhanced read range over the entire UHF RFID band and is suitable for worldwide deployment in different RFID bands.

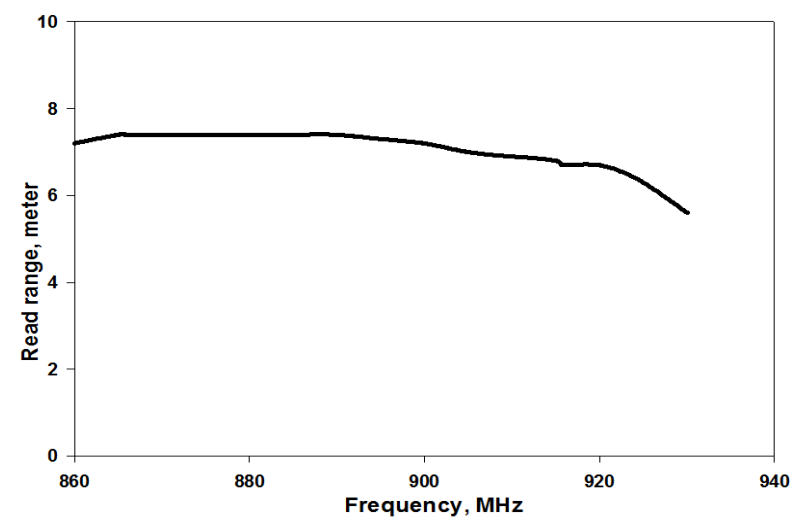

Figure 5: Variations in read range with frequency of the proposed UHF RFID tag based on modified dihedral corner.

The variation of read range of the proposed RFID tag with azimuth and elevation angular ranges at $866 \mathrm{MHz}$ (European) are shown in Fig.6 (a) and 6 (b). It is evident that a read range of 7.4 meters obtained for the proposed tag in free space. It can be seen from Fig. 6 (a) that the read range of the proposed tag remains constant in the azimuth angular range from $-48^{0}$ to $+48^{0}$ and beyond that the read range decreases on either side of azimuth angular range and reaches up to a minimum of 4.3 meter for $90^{\circ}$ From Fig. 6 (b), it is clear that the read range of the proposed tag remains constant in the elevation angular range from $-46^{\circ}$ to $+46^{\circ}$ and beyond that the read range decreases slightly on either side of azimuth angular range and reaches up to a minimum of 5.8 meter for $90^{\circ}$ It can be seen that the proposed tag offers enhanced read range over wider angular ranges.

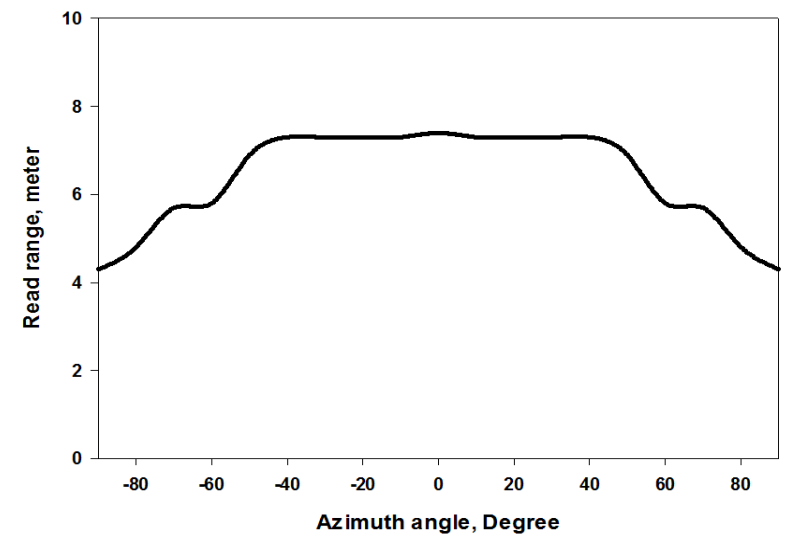

(a) 


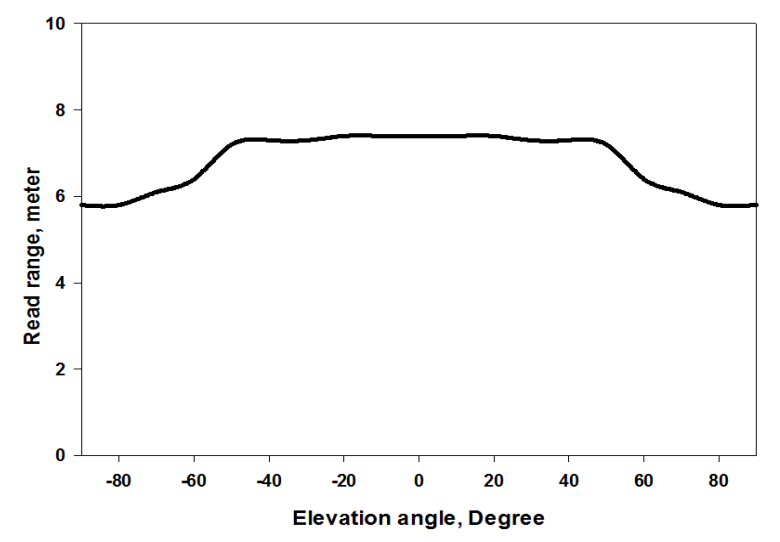

(b)

Figure 6: Variation of read range with angular range, $\mathrm{f}=$ $866 \mathrm{MHz}$.

(a) Read range Vs Azimuth angle, $\left(\Phi=0^{\circ}\right)$

(b) Read range Vs Elevation angle, $\left(\Theta=0^{\circ}\right)$

The Murata LXMS 31ACNA010 with an impedance of 12$\mathrm{j} 107 \Omega$ at $866 \mathrm{MHz}$ with threshold power $-8 \mathrm{dBm}$ used in this proposed UHF RFID tag based on modified dihedral corner tag antenna.

\begin{tabular}{|c|c|c|c|c|}
\hline Model & $\begin{array}{c}\text { RFIC \& } \\
\text { Threshold }\end{array}$ & $\begin{array}{l}\text { Size } \\
(\mathrm{mm})\end{array}$ & $\begin{array}{c}\text { Frequen- } \\
\text { cy }\end{array}$ & $\begin{array}{l}\text { Read } \\
\text { Range }\end{array}$ \\
\hline $\begin{array}{c}\text { Model.1 } \\
\text { (Ref } \\
\text { No.14) }\end{array}$ & $\begin{array}{l}\text { Alien } \mathrm{H} 2 \\
-14 \mathrm{dBm}\end{array}$ & $80 \times 80$ & $\begin{array}{c}840-960 \\
\mathrm{MHz}\end{array}$ & $3 \mathrm{~m}$ \\
\hline $\begin{array}{c}\text { Model .2 } \\
\text { (Ref } \\
\text { No.15) }\end{array}$ & $\begin{array}{l}\text { Alien H3 } \\
-18 \mathrm{dBm}\end{array}$ & $26.4 \times 24$ & $915 \mathrm{MHz}$ & $2.8 \mathrm{~m}$ \\
\hline $\begin{array}{c}\text { Commer- } \\
\text { cial tag } \\
\text { MINIWEB } \\
\text { (Ref } \\
\text { No.25) } \\
\end{array}$ & $\begin{array}{l}\text { NXP U- } \\
\text { Code G2il } \\
-18 \mathrm{dBm}\end{array}$ & $40 \times 18$ & $\begin{array}{c}860-960 \\
\mathrm{MHz}\end{array}$ & $\approx 4 \mathrm{~m}$ \\
\hline $\begin{array}{c}\text { Proposed } \\
\text { Tag }\end{array}$ & $\begin{array}{c}\text { Murata } \\
\text { LXMX } 31 \\
\text { ACNA010 } \\
\text {-8dBm }\end{array}$ & $\begin{array}{c}\mathrm{L}_{1}=75 \\
\mathrm{~W}_{1}=65 \\
\mathrm{~W}_{2}=15\end{array}$ & $866 \mathrm{MHz}$ & $7.4 \mathrm{~m}$ \\
\hline
\end{tabular}

Table 1: Read range and size comparison of the proposed UHF RFID tag based on dihedral corner with some reported UHF RFID tags.

From Table 1, it can be seen that the proposed UHF RFID based on modified dihedral corner exhibits enhanced read range performance as compared to the other reported and commercially available tags. In the Table: 1, data for model 1 and model 2 are taken from the corresponding research papers and for the commercial tag (MINIWEB), the data is from the data sheet of the manufacturer [25]. Even though the physical size of the proposed tag is appreciably larger than the conventional tags, the enhanced read range over wide angular ranges with broadband characteristics is suitable for specialized applications like vehicle identification, sensor based RFID etc. The read range of the proposed tag could be enhanced further at least three times by using RFID chips with lower threshold values.

\section{Conclusions}

Design and development of a novel UHF RFID tag based on modified dihedral corner are presented. The proposed tag exhibits enhanced read range characteristics over the entire UHF RFID band which makes it suitable for worldwide deployment of them at different UHF RFID bands. The measured read range variations over the azimuth and elevation angular ranges exhibits wider coverage compared to commercially available tags.

\section{References}

[1] K. Finkenzeller, RFID Handbook, $3^{\text {rd }}$ edition. John Wiley \& Sons England 2010.

[2] Thomaskutty Mathew and John Bathelor, "RCS and Read Range of UHF RFID tag", Asia pacific International Symposium on Electromagnetic Compatibility, 978-1-4244-56239/10, 2010.

[3] P. V. Niktin, K. V. S. Rao and R.D. Martinez, "Differential RCS of RFID tag”, Electronic Letters, Vol.43, No.8, 2007.

[4] K. V. S. Rao, P. V. Niktin and S. F. Lam,"Antenna design for UHF RFID tags; a review and a practical application", IEEE transactions on Antennas and Propagation, Vol.53, No12, pp.3870-3876, 2005.

[5] Y. Choi, U. Kim, J. Kim, J. Choi, "Design of modified folded dipole antenna for UHF RFID tag", Electronics letters, 45(2009), 387-389.

[6] D. Diugwu, J. Bachelor, T. Mathew, "Complementarity in the optimization of RFID dipole tag antennas", In.Symp.on Proceedings of IEEE antennas and propagations society international symposium, 1-4, SanDiego, California,2008.

[7] Mai, O. Salman, Ezzeldin, A. Soliman, Guy, A.E, Vandenbosch, Walter De Reedt, "Novel Electrically small Meander line RFID tag Antenna", International Journal of $R F$ and Microwave Computer-Aided Engineering, Vol. 23 No.6, November 2013.

[8] Gaetano Marroco, "Gain-Optimized Self-Resonant Meander Line Antennas for RFID Applications", IEEE Antennas and Wireless Propagation letter, Vol.2, 2003.

[9] Ukkonen, L. and L. Sydanheimo, "Impedance matching consideration for passive UHF RFID tag", Asia Pacific Microwave Conference, 2367-23-70, Singapore, 2009.

[10] Reich, M. T. and C. B. Reich, "UHF RFID impedance matching: When is a T-match not a T-match", IEEE International Conference on RFID, 23-30, Orlando, 2014.

[11] Manju, A. K. K. Aju john, J. K. Fijo, and T. Mathew, "UHF RFID dipole tag with modified multi-fractal 
cantor arms for enhanced read range", Microwave and Optical technology Letters, Vol.58, No. 5, 1173-1175, 2016.

[12] Marrocco, G., "The art of UHF RFID antenna design: Impedance-matching and size reduction techniques", IEEE Antennas and propagation Magazine, Vol. 50, 6679, 2008.

[13] H. T. Chou, J. C. Chu, and Y.Y. Kuo, "Size reduction of patch antenna using a meander line feeding structure for RFID applications", Microwave and Optical technology Letters, Vol. 56, 918-920, 2014.

[14] J.Z. Huang, P.H. Yang, W.C Chew, and T.T. Ye, "A Novel patch Antenna for Universal UHF RFID Tags", Microwave Opt. Letters, Vol.52, No.12, 2010

[15] Jibish, M. Manju, A. Anandan, C. K. and T. Mathew, "A broadband miniaturized UHF RFID dipole tag antenna with tapered meandered arms", Microwave and optical technology letters, Vol.59, No. 5, May 2017.

[16] K. K. Aju John, Manju. A, and T. Mathew, "SRR loaded compact UHF RFID tag for broadband operation", Progress In Electromagnetic Research C, Vol. 70, 175-182, 2016.

[17] J.H Yoon and K.S. Kwak, "Design of a half-bowtieshaped meander type micro strip patch antenna for wide independence bandwidth", Microwave and Optical technology Letters, Vol.44, 390-392, 2005.

[18] Currie, N.C, "Radar reflectivity measurement techniques and applications", Artech House, Norwood, MA, 1989.

[19] Knot, E.F, "RCS reduction of dihedral cross corners", IEEE Trans. Antennas Propag., 25, 1977, pp. 406-409.

[20] Ajaikumar, V., Jose K. A., Mohanan. P, and Nair K.G," reduction of radar cross section of corner reflectors using strip grating technique", proc. Int.Conf. On IEEE antennas and propagation, July 1992, Vol.2, pp. 707710

[21] Griesser. T, Balanis, C.A and Liu, K "RCS analysis and reduction for lossy dihedral corner reflectors", IEEE 1989, 77, pp. 806 - 814.

[22] Knot, E.F., Shaeffer, J.F., and Tuely, M.T, "Radar cross section", Artech House, Dedham, M.A, 4985.

[23] Ruck, G.T, Barrick, D.E., Stuart, W. D., Krichbraum, "Radar cross section hand book", Plenum Press, New York, 1970.

[24] Soresen, K.W, "A dihedral corner reflector model for full polarization calibration of RCS measurements", Proc. Int. Conf. on IEEE Antennas and Propagation. June 1991, Vol. 2, pp.748-751.

[25] https://www.smartrac-group.com/miniweb.html 